\title{
The Laser Enhanced Arc-Jet Facility (LEAF-Lite): Simulating Convective and Radiative Heating with Arc-jets and Multiple 50-kW CW Lasers
}

\author{
Geoff Cushman ${ }^{1}$ and Antonella Alunni ${ }^{2}$ \\ Jacobs Technology and AMA Inc., NASA Ames Research Center, Moffett Field, CA, 94035 \\ John Balboni ${ }^{3}$ and Pete Zell ${ }^{4}$ \\ NASA Ames Research Center, Moffett Field, CA, 94035 \\ Joe Hartman ${ }^{5}$ and Daniel M. Empey ${ }^{6}$ \\ Sierra Lobo and Jacobs Technology, NASA Ames Research Center, Moffett Field, CA, 94035
}

\begin{abstract}
LEAF-Lite (Laser Enhanced Arc-Jet Facility) is a radiative laser heating facility that has been added to the $60 \mathrm{MW}$ Interaction Heating Facility (IHF) convective plasma arc-jet located at NASA Ames Research Center. Together, these two systems can simulate both convective and radiative heating at heat fluxes reaching $551 \mathrm{~W} / \mathrm{cm}^{2}$ by simultaneously combining a highest measured heat flux of $160 \mathrm{~W} / \mathrm{cm}^{2}$ convective and $391 \mathrm{~W} / \mathrm{cm}^{2}$ radiative heating on a 152-mm $x$ 152-mm wedge model configuration. Adding radiant heating to an existing convective facility better simulates Earth atmospheric entry from hyperbolic lunarreturn speeds. The radiative heat is provided by multiple 50-kW CW IR lasers, which is nearly uniform across the illuminated surface with a total variation less than $6 \%$, while the convective heat is provided by a high enthalpy plasma arc-jet. In a later phase, the facility will expand to test panel test articles of $432-\mathrm{mm} \times 432-\mathrm{mm}$ and provide $100 \mathrm{~W} / \mathrm{cm}^{2}$ of radiative heating in a plasma convective flow environment. The paper describes this new combined heating capability, its current testing conditions, and the unique application of the laser system with respect to the Orion test flight lunar orbits.
\end{abstract}

\footnotetext{
${ }^{1}$ Optical Engineer, Thermophysics Facilities, (TSF) MS 230-3, Member AIAA

2 Research Scientist, Thermal Protection Materials Branch, (TSM) MS 234-1, Member AIAA

${ }^{3}$ Research Engineer, Thermophysics Facilities, (TSF) MS 229-4

${ }^{4}$ Project Manager, Code P, MS 244-6

${ }^{5}$ Senior Consultant, Thermophysics Facilities, (TSF) MS 229-3

${ }^{6}$ TSF/TSM Branch Manager, NASA Ames Research Center, MS 229-3
} 


\section{Nomenclature}

\begin{tabular}{|c|c|}
\hline$A E D C$ & $=$ Arnold Engineering Development Complex \\
\hline$B P E$ & $=$ Beam Path Enclosure \\
\hline$C L$ & $=$ Center Line \\
\hline$C W$ & $=$ Continuous Wave \\
\hline CWHF & $=$ Cold Wall Heat Flux \\
\hline EFT-1 & $=$ Exploration Flight Test 1 \\
\hline$E M-1($ or 2$)$ & $=$ Exploration Mission 1 or 2 \\
\hline IHF & $=$ Interaction Heating Facility \\
\hline$I R$ & $=$ Infrared \\
\hline IST & $=$ Integrated Systems Test \\
\hline$L E$ & $=$ Leading Edge \\
\hline LEAF-Lite & $=$ Laser Enhanced Arc-jet Facility \\
\hline LEO & $=$ Low Earth Orbit \\
\hline LHEML & $=$ Laser Hardened Materials Evaluation Laboratory \\
\hline$O E$ & $=$ Optics Enclosure \\
\hline OFHC & $=$ Oxygen-free High Thermal Conductivity \\
\hline$R C G$ & $=$ Reaction-cured Glass \\
\hline$S L S$ & $=$ Space Launch System \\
\hline SNEG & $=$ Super Near-Infrared Enhanced Gold \\
\hline$T P S$ & $=$ Thermal Protection System \\
\hline$U V$ & $=$ Ultraviolet \\
\hline
\end{tabular}

\section{Introduction}

$\mathrm{T}$ he National Aeronautics and Space Administration, along with other commercial space companies, have interest in testing Thermal Protection System (TPS) materials used in heat shields in both convective and radiative conditions on a single test article. Future NASA and commercial crew vehicles, such as the Orion Multi-Purpose Crew Vehicle (MPCV) and other robotic entry systems, will experience high heat flux from a Lunar or Martian return trajectory. Due to this high energy entry, the hypervelocity shock layer will radiate and significantly contribute to the overall heating on the heat shield. The Exploration Flight Test Mission 1 (EFT-1), conducted in December of 2014 experienced both radiative and convective heat fluxes when it returned to Earth at $8.9 \mathrm{~km} / \mathrm{s}(81.9 \%$ of the velocity of a lunar return mission $)^{[1]}$. Exploration Mission 1 (EM-1), Orion's first launch on the Space Launch System (SLS), will experience a higher return velocity and heat flux due to returning from a lunar trajectory. Specifically, the Orion compression pads will experience $150-280 \mathrm{~W} / \mathrm{cm}^{2}$ of radiant heat flux and $400-500 \mathrm{~W} / \mathrm{cm}^{2}$ of convective heating at pressures between 20 and $25 \mathrm{kPa}$. Current NASA plans are to launch Exploration Mission 2 (EM-2), which will be the first Orion manned space flight after a successful EM-1 mission. Both EM-1 and EM-2 will return from the moon and experience significantly higher radiative heating compared to EFT-1.

It is imperative that these heatshields are tested in a ground based facility that can most accurately represent the heating environments over long durations. High enthalpy plasma facilities at NASA Ames Research Center and those at Arnold Engineering Development Complex (AEDC) provide only convective heating environments for TPS development and flight system validation while laser facilities like the Laser Hardened Materials Evaluation Laboratory (LHEML) provide only radiative heating. The ability to test wedge articles in combined radiative and convective environments has been missing from TPS testing. Adding a radiative component onto a convective arc-jet facility allows TPS materials to be exposed to both heating modes at the same time, better representing an actual atmospheric entry. This is the exact goal of the Laser Enhanced Arc-Jet Facility: to add a radiative heating element to a preexisting convective arc-jet. The LEAF-Lite system does this by simulating radiant heating using multiple 50-kW continuous wave $(\mathrm{CW})$ infrared (IR) lasers to illuminate a test article while the arc-jet provides a convective heating environment. Specifically, the convective heat is applied a test article while the radiant heat simultaneously illuminates the test article from the side. LEAF-Lite testing of Orion TPS, including the tiled Avcoat heatshield and compression pads, is a requirement for EM-2 certification of flight readiness. 
Radiative heating from the shock layer during atmospheric entry encompasses a broad spectral range from the ultraviolet (UV) into the IR. Ideally, testing at high intensities over all of these wavelengths is optimal. However, there are no light sources that can illuminate a wedge or panel configuration with a high heat flux while spanning the relevant spectral range. Besides high power lasers, simulations of radiant heating include xenon arc lamps and IR diode arrays but an IR fiber laser system was chosen for LEAF-Lite for multiple reasons. First, there have been many technical breakthroughs in fiber lasers throughout the past few decades that allow these lasers to achieve extremely high power levels. Fiber lasers can now reach the power levels that $\mathrm{CO}_{2}$ gas lasers can achieve without many drawbacks associated with gas lasers. These fiber lasers are used in a variety of military and private sector systems for tasks ranging from directed energy projects to industrial welding. Additionally, a laser beam offers more control over the directed energy compared to a lamp or diode array. However, there are some drawbacks to using fibers lasers. As mentioned above, the light emitted from these lasers is monochromatic at $1070 \pm 4 \mathrm{~nm}$. In the future, if practical multi-kilowatt visible and UV lasers become available, it may be possible to build a ground-test facility to expose TPS materials over a broader spectral range. When simulating a radiant heating source, it is not practical to use a pulsed laser because a sample may be exposed for much longer than a single laser pulse. Instead, a CW laser must be used to heat a TPS material for a longer duration. Using lasers to simulate radiant heating is not new and has even been implemented at NASA Ames in the $1970 \mathrm{~s}^{[2]}$. However, wedge and panel test articles have never been exposed to uniform radiant heating $( \pm 6 \%)$.

NASA Ames Research Center has taken the Interaction Heating Facility (IHF), which can produce a convective environment up to $160 \mathrm{~W} / \mathrm{cm}^{2}$ on a wedge configuration with a 9" nozzle, and added multiple 50-kW fiber lasers to simulate radiative heating. The system has provided uniform ( $\pm 6 \%$ ) square heating on a $152-\mathrm{mm} \times 152-\mathrm{mm}$ (6" x 6") wedge test article up to $375 \mathrm{~W} / \mathrm{cm}^{2}$ and will provide $100 \mathrm{~W} / \mathrm{cm}^{2}$ on a $432-\mathrm{mm} \times 432-\mathrm{mm}$ panel test article.

\section{Fiber Laser Theory and Laser Specifications}

As noted in the introduction, there have been revolutionary breakthroughs in fiber laser technology in the past two decades. Fiber lasers can achieve extremely high powers, are durable, and can be regularly serviced by the laser manufacturing company.

However, as advanced as these lasers are, they still operate on the fundamental principles of any laser. Namely, there must be a cascade of stimulated emissions from a transition between an upper and lower energy state of either an atom, ion, or molecule. Many different types of lasers exist with a variety of lasing medium such as gas, crystals, and diodes. However, a fiber laser uses sections of rare-earth-doped optical fiber as the lasing medium. LEAF-Lite's lasers are Ytterbium +3 doped fiber lasers.

\section{LEAF-Lite Laser Details}

LEAF-Lite uses four $50-\mathrm{kW}$ CW fiber lasers built by IPG Photonics (Figure 1). Each of these lasers contains 46 individual laser modules, each capable of outputting roughly

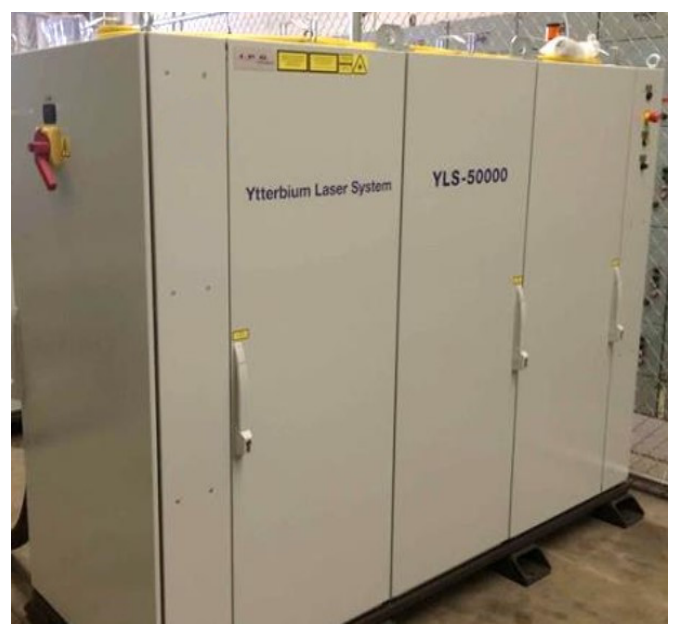

Figure 1. IPG YLS 50000

$1.2 \mathrm{~kW}$, that combine into one output fiber. As a result, the max output power ranges from about 51 to $53 \mathrm{~kW}$. The lasers can reach max power in about 33 microseconds and shutoff in 15.6 microseconds, far quicker than a $\mathrm{CO}_{2}$ laser or conventional gas laser. Because thermal dissipation is not trivial, LEAF-Lite uses two Riedel PC 400.01 industrial chillers per laser. With all chillers running simultaneously, the system can operate and emit for 20 minutes at full power. The main output fiber is a multimode 200 micron fiber that extends 25-30 meters, allowing for the lasers to be stored in a separate room than the Optics Enclosure. These fibers are armored and can detect when a severance occurs and immediately shuts down the system. They also terminate in a special connector that mates and locks directly into the system's collimator. In the unlikely event that the fiber ever decouples from the collimator, a built-in interlock will trip and immediately shut down the laser. Like most lasers, laser power is only linear after a $10 \%$ power threshold has been exceeded. When all laser modules are activated, minimum power is approximately $5 \mathrm{~kW}$ per laser. However, it is possible to selectively activate individual modules in order to reach a much lower output power. With only one module activated, the final laser output can be in the hundreds of watts. This capability is extremely useful when a much lower power is needed. 


\section{Description of LEAF-Lite Setup}

\section{$\underline{\text { Laser System }}$}

The LEAF-Lite system houses the four 50-kW lasers outside of the building that contains the IHF and routes each laser's main output fiber through a cable tray into a room called the Optics Enclosure (OE). Here, each beam is manipulated and then sent through a window into the IHF vacuum test chamber. Each laser's light is manipulated in its own beam path before combining onto the test article inside the test chamber.

Figure 2 shows the optics table with a red line representing the laser at different points. First the fiber laser is attached to a three lens collimator. The output light from the collimator has a Gaussian intensity profile and can be seen at point 1 . Next, the light is reflected off our Oxygen-free High Thermal Conductivity (OFHC) copper integrator with a 99.7\% reflective Super Near-Infrared Enhanced Gold (SNEG) coating. The integrator focuses the beam to a 1 $\mathrm{cm}$ by $1 \mathrm{~cm}$ uniform square roughly halfway between this optic and the next. This is depicted at point 2 in Figure 2 . We now have our system image and need to enlarge this square and project it up and out into the vacuum chamber. Third, laser light is reflected off a re-imaging mirror with a radius of curvature of $1200 \mathrm{~mm}$, shown in point 3 in Figure 2. From here, two flat steering mirrors project the light up and out of the OE and towards the IHF vacuum test chamber.

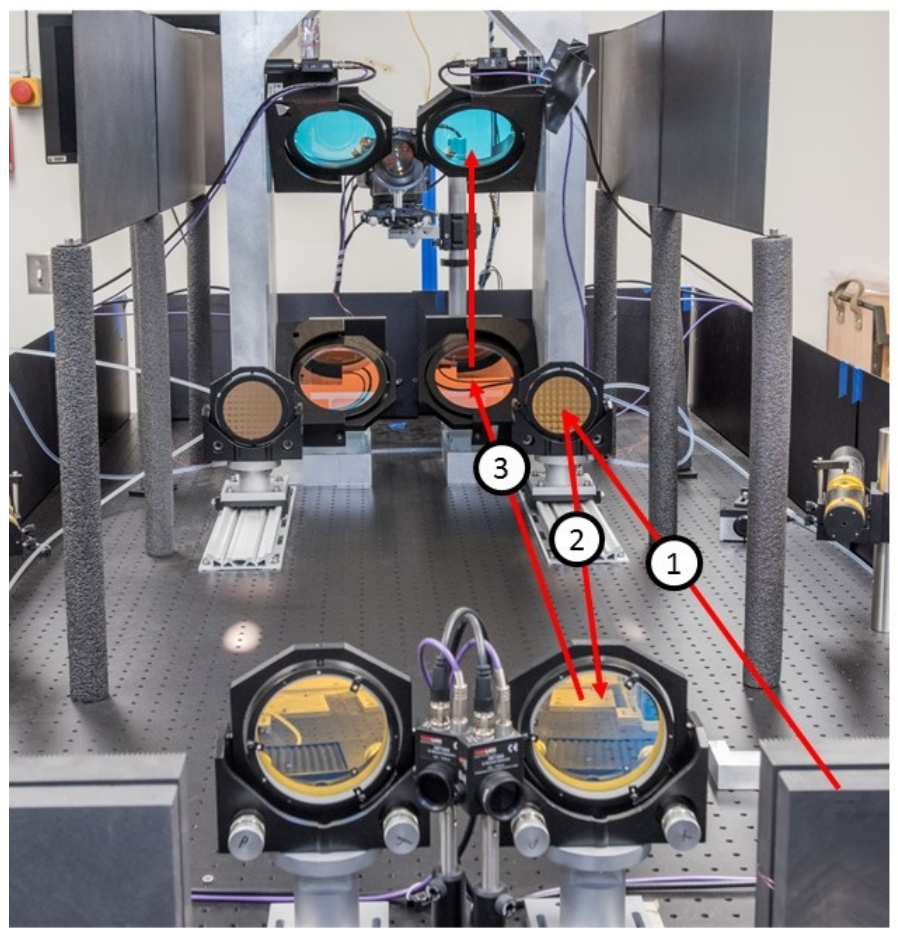

Figure 2. The LEAF-Lite optical layout. Pictures were taken with a red guide beam.
1) Gaussian beam emerges from collimator

2) Beam at the focus of the integrator $(1 \mathrm{~cm}$ $\mathrm{x} 1 \mathrm{~cm}$ square spot)

3) Converging beamlets to be reimaged at scatterplate
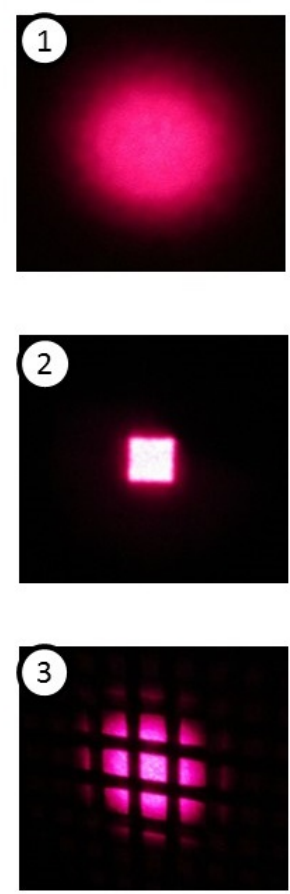

*Images of red guide beam

Finally, the light passes through a beam path enclosure (BPE), a safety enclosure that confines the open beam between the OE to the IHF test box, and through a main pressure window into the vacuum chamber. There is also a thin inner protection window to guard the main window from ablation debris from the model. The protection window is designed to be swapped out whenever damaged beyond repair. The target, either a $152-\mathrm{mm} \times 152-\mathrm{mm}$ wedge or a 432-mm x 432-mm panel test article is angled from $0^{\circ}$ to $45^{\circ}$ for wedges or $-5^{\circ}$ to $6^{\circ}$ for panels.

As noted earlier, the LEAF-Lite system can test in two possible configurations: a wedge configuration (Figure 3) which produces a $152-\mathrm{mm} \times 152-\mathrm{mm}$ square spot, and a panel configuration (Figure 4) that produces a $432-\mathrm{mm} \times$ 432-mm square spot. Changing optics between configurations takes a couple of hours and requires different integrators, reimaging mirrors, and a larger sized window. Figures 3 and 4 show the wedge and panel configurations, respectively, and how the laser travels from the $\mathrm{OE}$ to the IHF test box. 


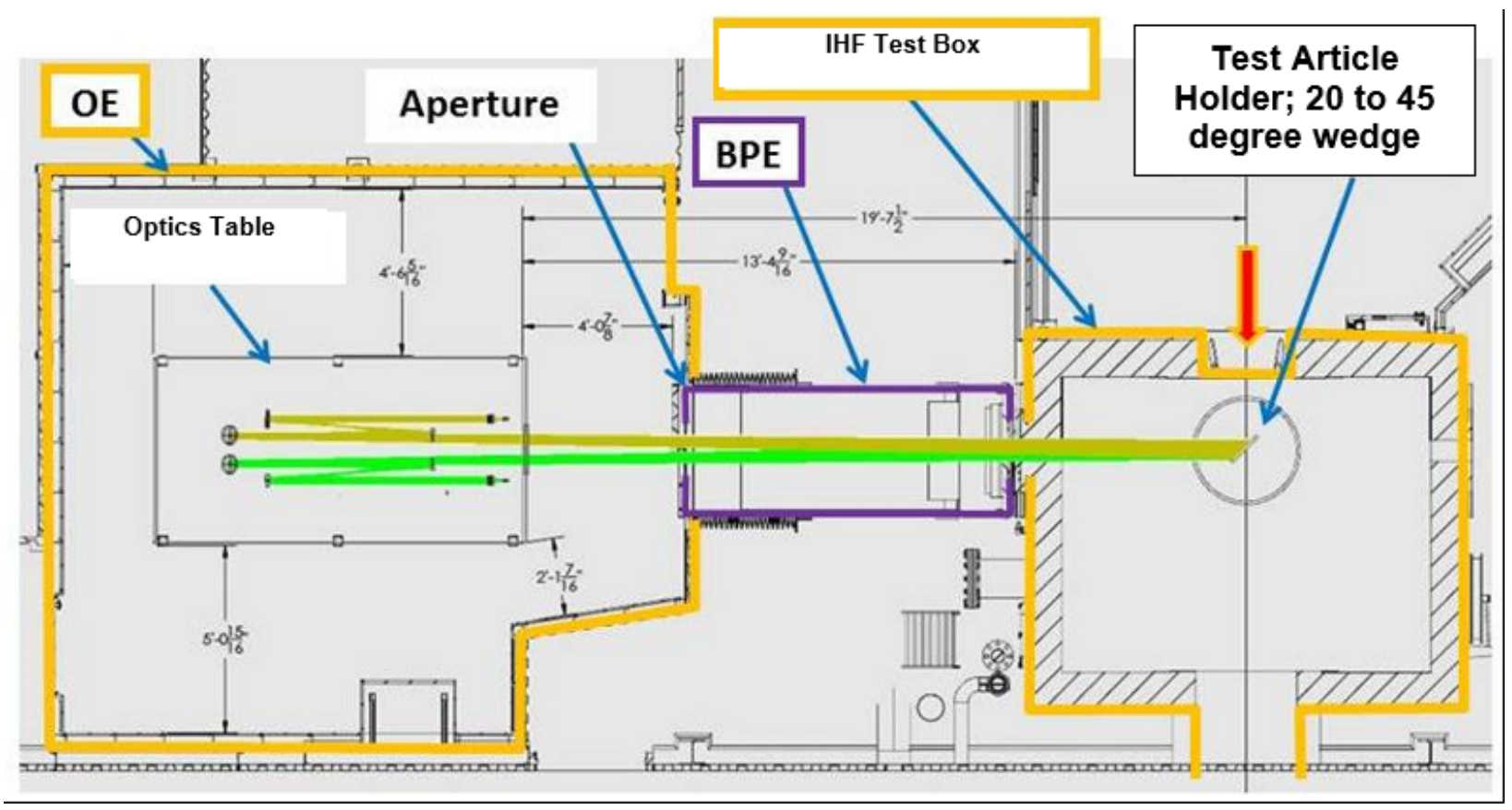

Figure 3. Two 50-kW beams used in the wedge configuration. Convective flow represented as red arrow.

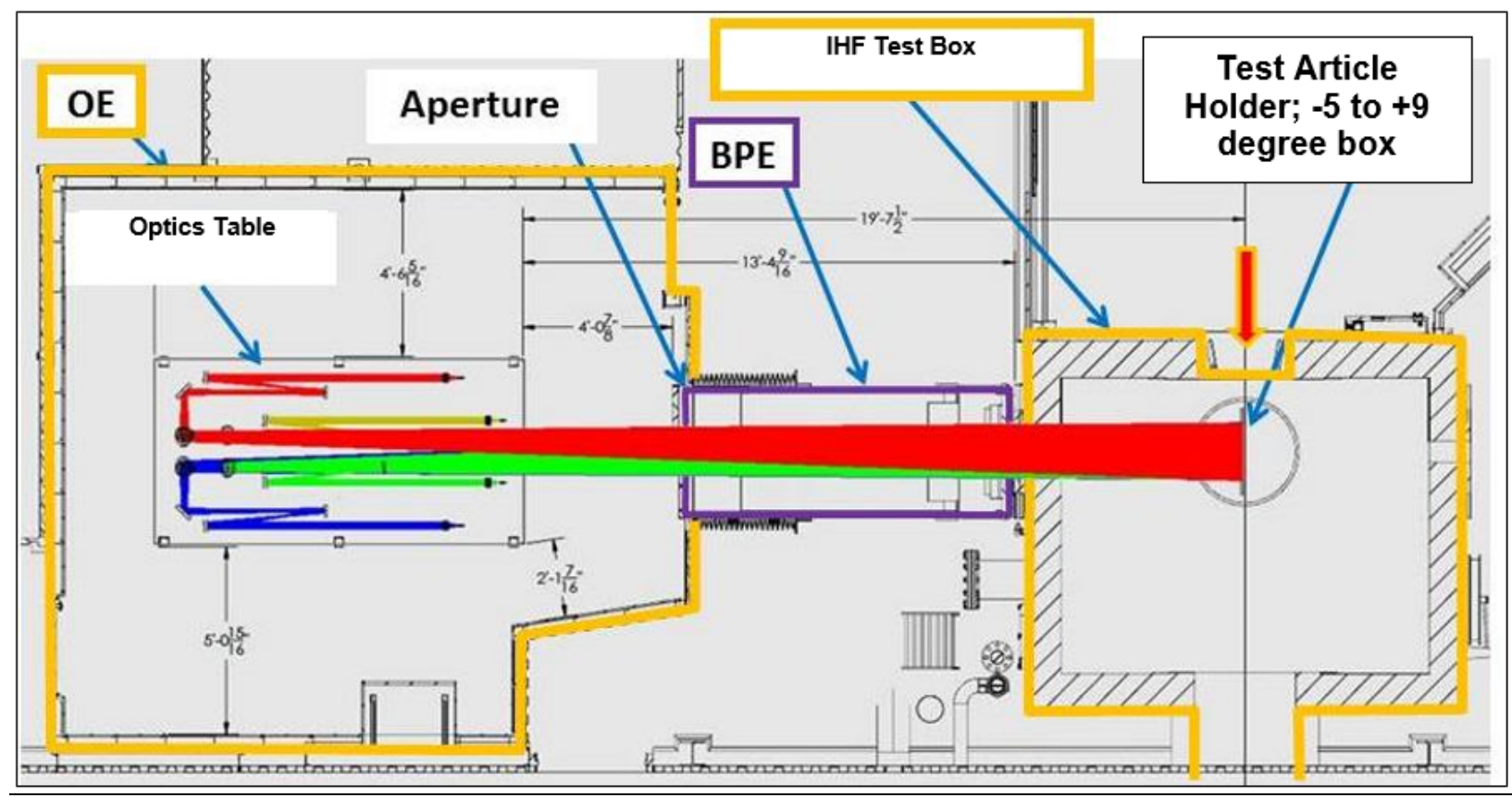

Figure 4. Four 50-kW beams used in the panel configuration. Convective flow represented as red arrow.

Control of the laser is accomplished through a new custom controller system interface. An operator, after configuring for single or multi-laser operation, inputs a desired program containing laser power variations over a desired time-varying profile. Laser emission can only begin when a model swings into the facility centerline (CL) so as not to illuminate the back wall of the test chamber. 


\section{Convective Heating Upgrades}

Although this paper mainly focuses on the new radiative heating capability of the IHF at NASA Ames, it is important to note the new changes to the convective heating capability as well.

\section{9-inch Nozzle for Wedge Tests}

The goal of the wedge test configuration is to apply a uniform square beam of 152-mm x 152-mm onto the surface of a wedge test model exposed to the IHF arc-jet free stream. Before this upgrade, the IHF only had the ability to use a 6" or a 13 " nozzle. The 6" nozzle provided an adequate heating to an area of 4.5 " x 4.5 " (114-mm x 114-mm), which is too small for Orion requirements. On the other hand, the larger expansion ratio of the 13" nozzle provided a much lower heat flux to the required $152-\mathrm{mm} \times 152-\mathrm{mm}$ test article size. As a result, a 9" conical nozzle was developed to test $152-\mathrm{mm} \times 152-\mathrm{mm}$ test articles at the desired convective heat fluxes. The intermediate nozzle fills the capability gap between a 6 " and a 13" nozzle. Additionally, a new $20^{\circ}$ wedge model was fabricated to hold a $152-\mathrm{mm} \times 152-\mathrm{mm}$ test article to be used with the new 9" nozzle. A picture of the 9" nozzle can be seen in Figure 5.

\section{Future Truncated Semi-Elliptic Nozzle for Panel Test}

A new truncated semi-elliptic nozzle will be needed for LEAF-Lite's panel configuration where a 432-mm x 432-mm target will be tested in the future. With dimensions of approximately 21.5 " width and 5.5 " height, the nozzle will interface with the IHF's deionized water cooling system, vacuum test chamber, and supports full-power LEAF-Lite laser capability. Additionally, a new model holder box has been designed and fabricated to hold a 432-mm x 432-mm test article and will accommodate approximate $-5^{\circ}$ to $+6^{\circ}$ angle of attack to the plasma flow. This LEAF-Lite configuration is designed to operate using four $50-\mathrm{kW}$ CW IR lasers for a total emitted power of $200 \mathrm{~kW}$. When this nozzle and laser combination is activated in late 2018, information will be released describing its performance capabilities.

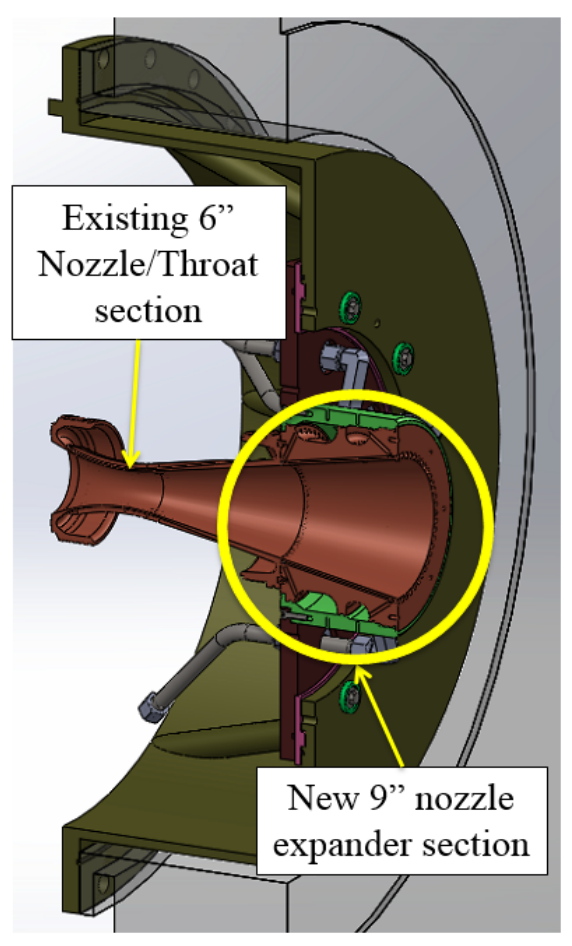

Figure 5. Nine inch nozzle attached to existing six inch throat

\section{Instrumentation and Safety Systems}

When working with a laser in any system, laser safety should always be considered; however, when working with multiple $50-\mathrm{kW} \mathrm{CW}$ lasers, laser safety must be top priority. Because severe injury or death can occur when working with these high power lasers, the LEAF-Lite system uses multiple engineered, procedural, and administrative safety requirements in order to contain the beam. First, there are many personnel exclusion zones that workers are not allowed to occupy during a run. No one is allowed in the OE when the 50-kW lasers are activated and all high-power laser operations are conducted from the IHF control room. A wide variety of instruments work to constantly monitor laser diagnostics during a run. For example, video surveillance, photodetectors, and thermocouples are used extensively throughout the system. Nominal readings from the monitoring instruments were acquired during our initial systems test. These bassline values were used to determine appropriate thresholds for warnings and automatic system shutdowns.

Additionally, not only are personnel not allowed inside the OE when the high-power lasers are active, a Kirk key system connected to the laser power supply makes it impossible to enter the $\mathrm{OE}$ in normal operation without disconnecting power to the 50-kW lasers. This trapped key interlock ensures that the correct and safe procedure must be followed in order to begin laser operation. Multiple emergency stop buttons are located throughout the system and can easily be accessed if anyone deems an emergency shutdown is necessary. 


\section{Integrated System Testing and Results}

LEAF-Lite's Integrated System Test (IST) was conducted throughout the month of October in 2017. The goal was to fully test LEAF-Lite in the wedge configuration (152-mm x 152-mm uniform square), illuminating several test articles such as burn plates, a convective and radiative calibration plate, a reaction-cured glass (RCG) coated TPS tile with multiple near-surface thermocouples, and Avcoat TPS samples. A sample of Avcoat was tested at independent radiative and convective conditions, and three Avcoat test samples were exposed to combined radiative and convective heat flows. All samples were approximately $152-\mathrm{mm} \times 152-\mathrm{mm}$ and were tested on a $20^{\circ}$ wedge. Because testing only involved the wedge configuration, only two $50-\mathrm{kW}$ lasers were used.

As with any new system, several challenges were overcome during testing, and ultimately this test successfully concluded with no major problems. This section will focus on LEAF-Lite's performance and the test conditions that are possible with the new capability. Although Avcoat was tested, this paper will not present an indepth analysis on those test articles.

The results that follow are from a set of five radiative conditions, labeled R1-R5, and a set of three convective conditions, labeled C1-C3, with cold-wall heat flux (CWHF) targets listed in Table 1. The R type represents radiant heating by laser emission while the $\mathrm{C}$ type represents only convective flow heating via arc-jet operation. The $\mathrm{R} 5$ row below displays "max" because the maximum irradiance was unknown at the beginning of the test. This value was later averaged to be $391 \mathrm{~W} / \mathrm{cm}^{2}$.

Table 1. Radiative and convective conditions used during the IST.

\begin{tabular}{|c|c|}
\hline $\begin{array}{c}\text { Condition } \\
\text { Name }\end{array}$ & $\begin{array}{c}\text { Target } \\
\text { CWHF } \\
\left(\mathrm{W} / \mathrm{cm}^{2}\right)\end{array}$ \\
\hline $\mathrm{R} 1$ & 30 \\
\hline $\mathrm{R} 2$ & 80 \\
\hline $\mathrm{R} 3$ & 160 \\
\hline $\mathrm{R} 4$ & 300 \\
\hline $\mathrm{R} 5$ & $\max$ \\
\hline $\mathrm{C} 1$ & 30 \\
\hline $\mathrm{C} 2$ & 80 \\
\hline $\mathrm{C} 3$ & 160 \\
\hline
\end{tabular}

\section{A. Water-Cooled Calibration Plate}

\section{Radiative Calibration Results}

In early radiative tests, a series of burn plates, one of which is shown on the left in Figure 6, was used to burn an image of the square beam into black PMMA plastic. These burn plates were used to check alignment, beam overlap, and serve as an initial tool to assess beam uniformity prior to measuring heat flux on a radiative calibration plate, which is shown on the right in Figure 6. 
R3 Burn Plate

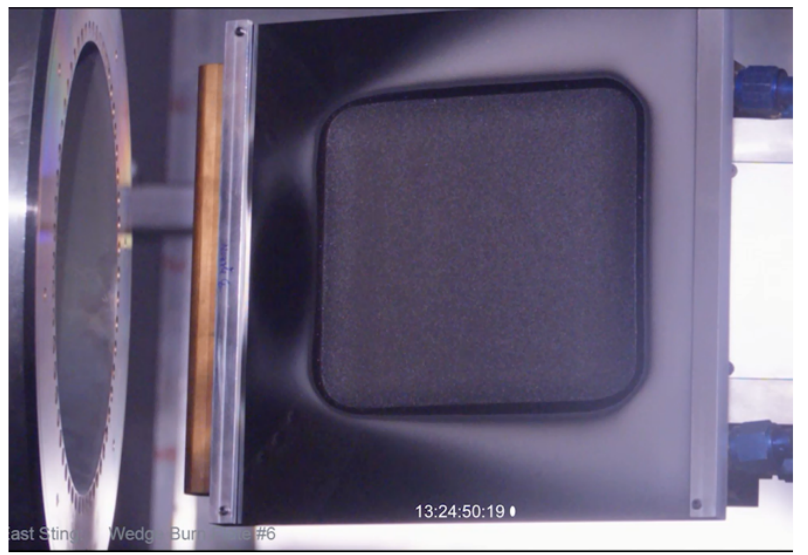

R3 Cal Plate

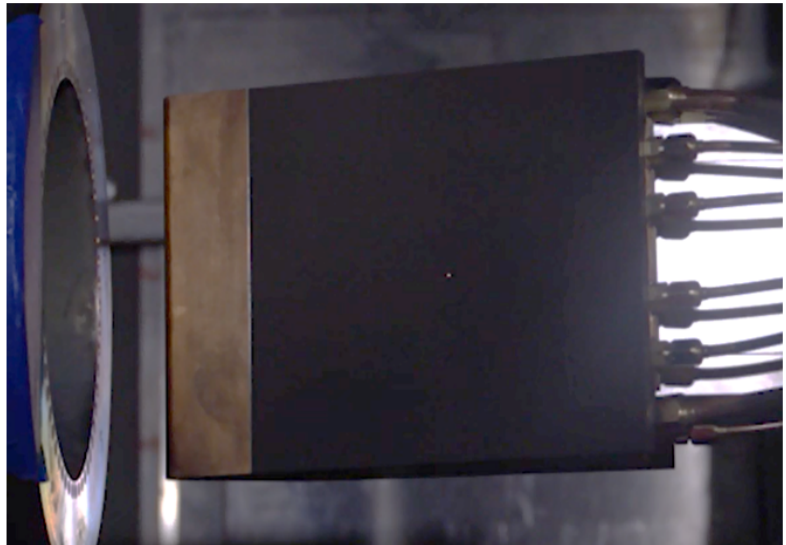

Figure 6. Video stills from R3 condition on burn and cal plate. Note that this camera was fitted with a filter to remove 1070-nm light so the laser is not visible.

Separate radiative and convective calibration plates, shown in Figure 7, were used to measure cold wall heat flux at different locations within the 152-mm x 152-mm test region. Both the radiative and convective calibration plate are made of water-cooled copper and use six Gardon gauges, whose placement is illustrated in Figure 8.

Convective Cal Plate

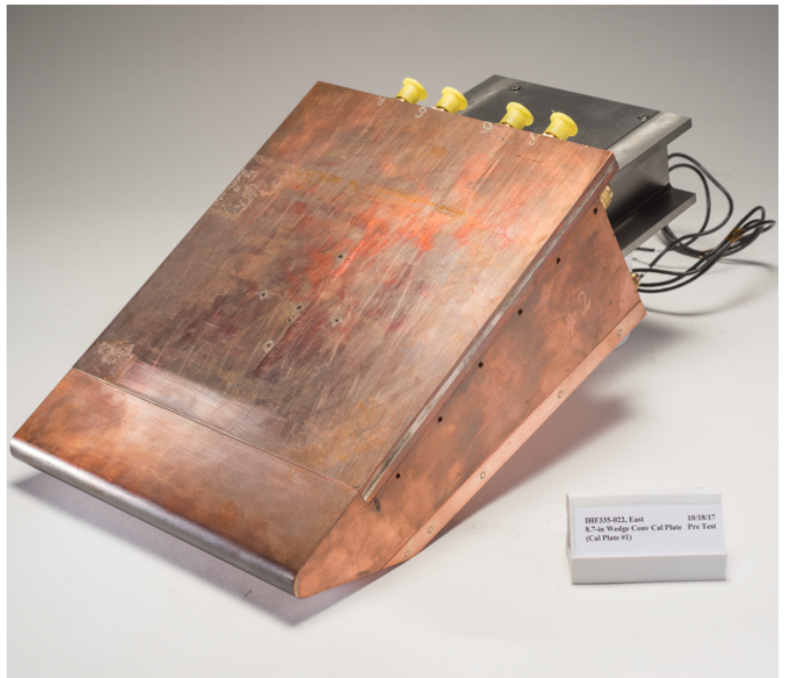

Radiative Cal Plate

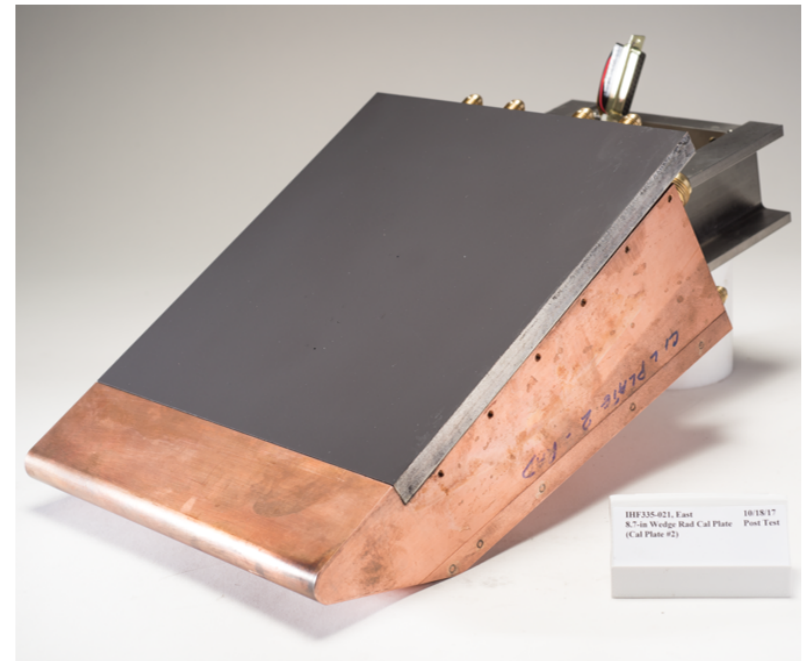

Figure 7. Convective cal plate (left) and radiative cal plate (right). The radiative cal plate was coated with black VHT SP102 high emissivity paint and did not take pressure measurements. 


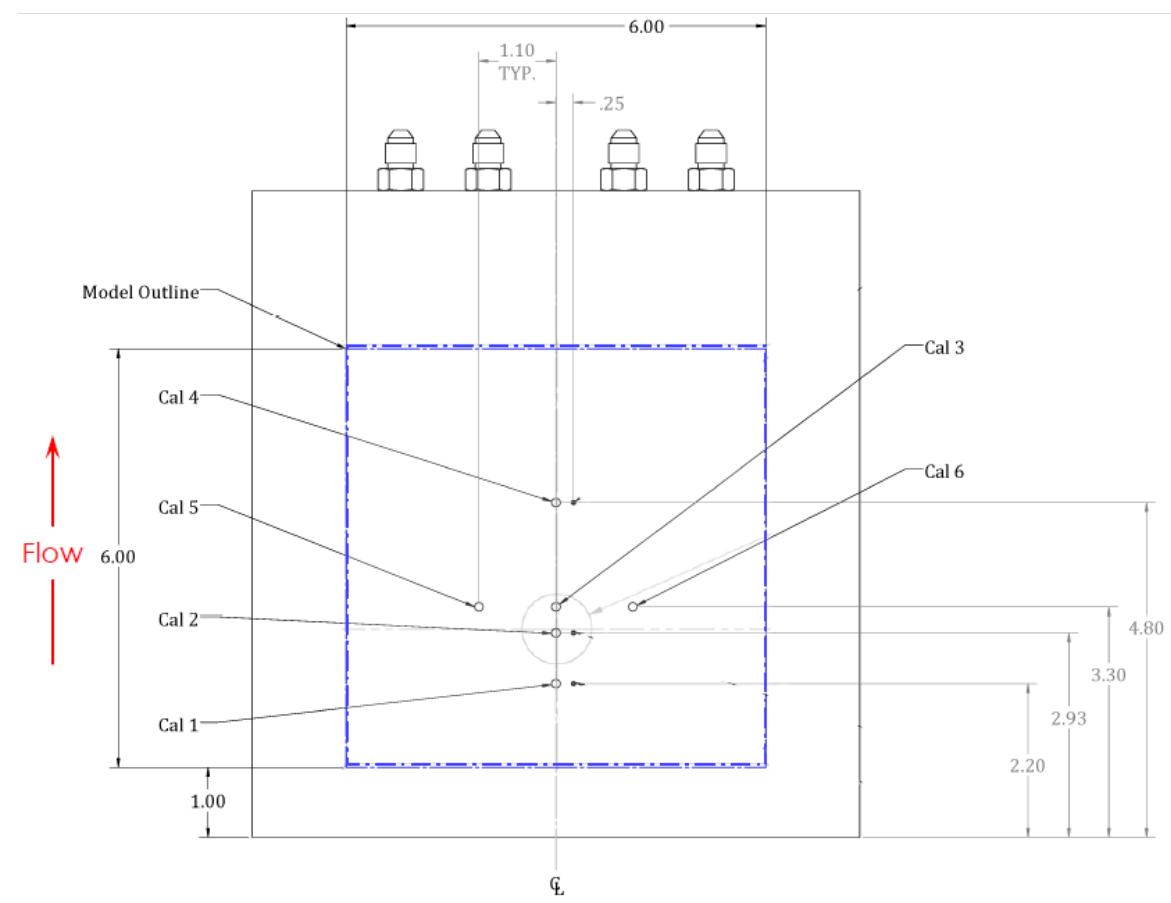

Figure 8. Location of calorimeters on the calibration plate. The radiative plate did not take pressure measurements while the convective plate had pressure transducers 0.25 inches to the right of Cal 1, Cal 2, and Cal 4

The copper plate used for radiative calibration runs was coated with black VHT SP102 paint to decrease reflection, increase absorption, and achieve more accurate heat flux measurements. Emissivity of the paint was determined to be 0.95 when functional, which was the case for most runs. The paint remained intact and the plate produced reliable heat flux measurements throughout runs conducted at the R1-R3 conditions. However, during an initial high-power run, the ramp-up to the R4 condition was too rapid, resulting in aggressive decomposition of the paint and potentially erroneous heat flux measurements. As a result, such runs were discarded and slower ramp-up over five seconds and shorter dwell times of no more than two seconds were conducted for subsequent high-power runs. This run characteristic was only applied to the cal plate and no other test article.

Results from each condition along the centerline of the calibration plate are presented in Table 2 and graphed in Figure 9. Similarly, results across centerline of the calibration plate are shown in Table 3 and graphed in Figure 10. Single runs with the radiative calibration plate were completed for conditions R1, R2, and R5, which was defined as the maximum laser power condition with maximum heat flux reaching $405 \mathrm{~W} / \mathrm{cm}^{2}$. Multiple runs were conducted at conditions R3 (four runs) and R4 (two runs), so the values listed in the tables are averaged from multiple sets of heat flux measurements for those conditions. Across all five conditions, the results indicate that the beam is uniform within $6 \%$ of the average irradiance. And for conditions R3 and R4, measurements across multiple runs suggest run-to-run variability is within $11 \%$. Uncertainty is estimated to be $\pm 3 \%$, the estimated accuracy of commercial off the shelf Gardon gauges. ${ }^{[3]}$

Table 2. Averaged irradiance data along centerline.

\begin{tabular}{|c|c|c|c|c|c|}
\hline & $\begin{array}{c}\mathrm{R} 1 \\
\left(\mathrm{~W} / \mathrm{cm}^{2}\right)\end{array}$ & $\begin{array}{c}\mathrm{R} 2 \\
\left(\mathrm{~W} / \mathrm{cm}^{2}\right)\end{array}$ & $\begin{array}{c}\mathrm{R} 3 \\
\left(\mathrm{~W} / \mathrm{cm}^{2}\right)\end{array}$ & $\begin{array}{c}\mathrm{R} 4 \\
\left(\mathrm{~W} / \mathrm{cm}^{2}\right)\end{array}$ & $\begin{array}{c}\mathrm{R} 5 \\
\left(\mathrm{~W} / \mathrm{cm}^{2}\right)\end{array}$ \\
\hline Cal1 & 32 & 85 & 164 & 323 & 381 \\
\hline Cal2 & 30 & 84 & 166 & 332 & 395 \\
\hline Cal3 & 35 & 86 & 177 & 362 & 395 \\
\hline Cal4 & 33 & 84 & 171 & 350 & 382 \\
\hline Average & 32 & 85 & 169 & 342 & 388 \\
\hline
\end{tabular}




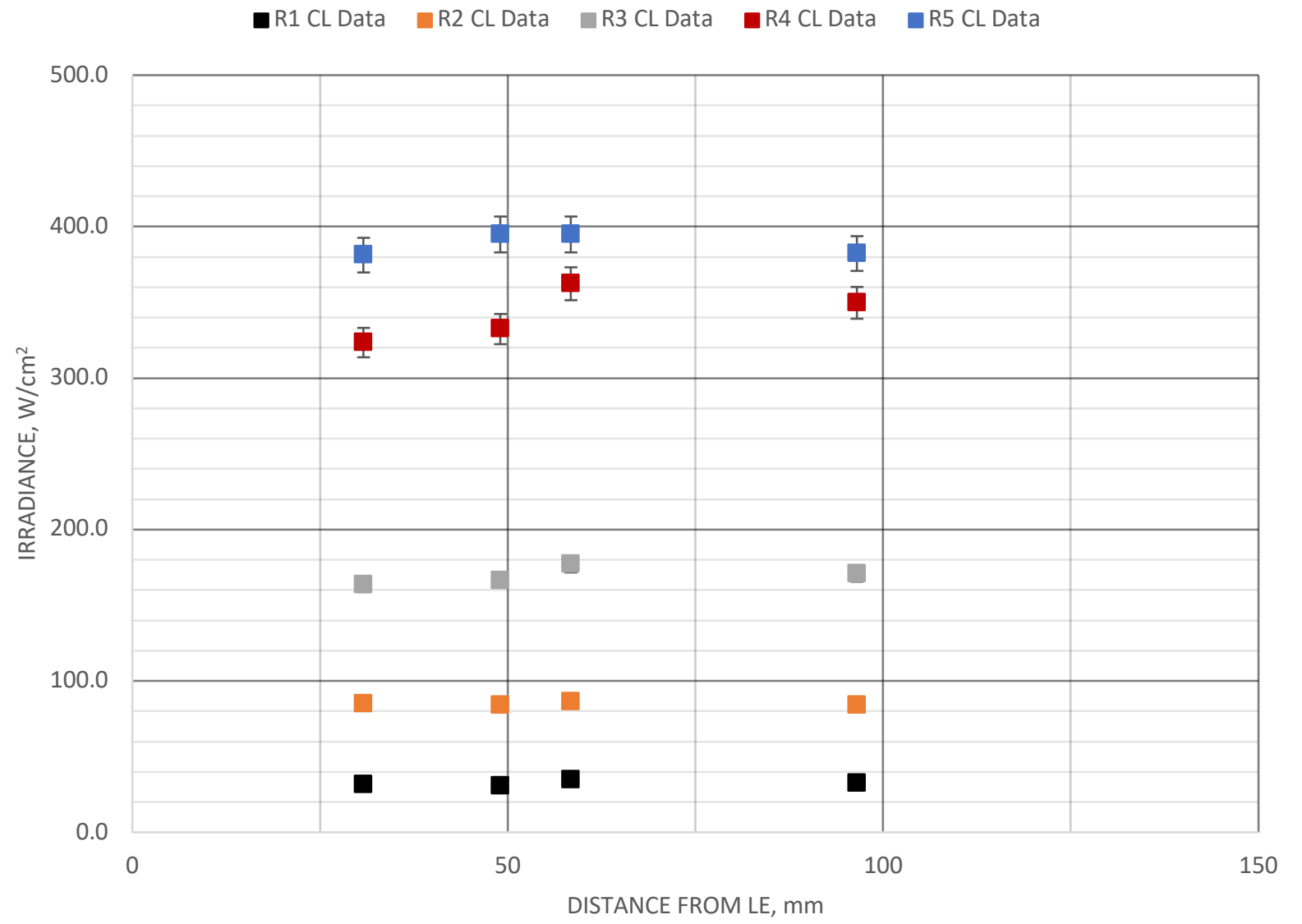

Figure 9. Radiative calibration along centerline. Graphed results from Table 2. Error bars are $\pm 3 \%$.

Table 3. Averaged irradiance data across centerline.

\begin{tabular}{|c|c|c|c|c|c|}
\hline & $\begin{array}{c}\mathrm{R} 1 \\
(\mathrm{~W} / \mathrm{cm} 2)\end{array}$ & $\begin{array}{c}\mathrm{R} 2 \\
(\mathrm{~W} / \mathrm{cm} 2)\end{array}$ & $\begin{array}{c}\mathrm{R} 3 \\
(\mathrm{~W} / \mathrm{cm} 2)\end{array}$ & $\begin{array}{c}\mathrm{R} 4 \\
(\mathrm{~W} / \mathrm{cm} 2)\end{array}$ & $\begin{array}{c}\mathrm{R} 5 \\
(\mathrm{~W} / \mathrm{cm} 2)\end{array}$ \\
\hline Cal5 & 33 & 80 & 165 & 332 & 405 \\
\hline Cal3 & 35 & 86 & 177 & 362 & 395 \\
\hline Cal6 & 32 & 80 & 167 & 340 & 391 \\
\hline Average & 33 & 82 & 170 & 345 & 397 \\
\hline
\end{tabular}




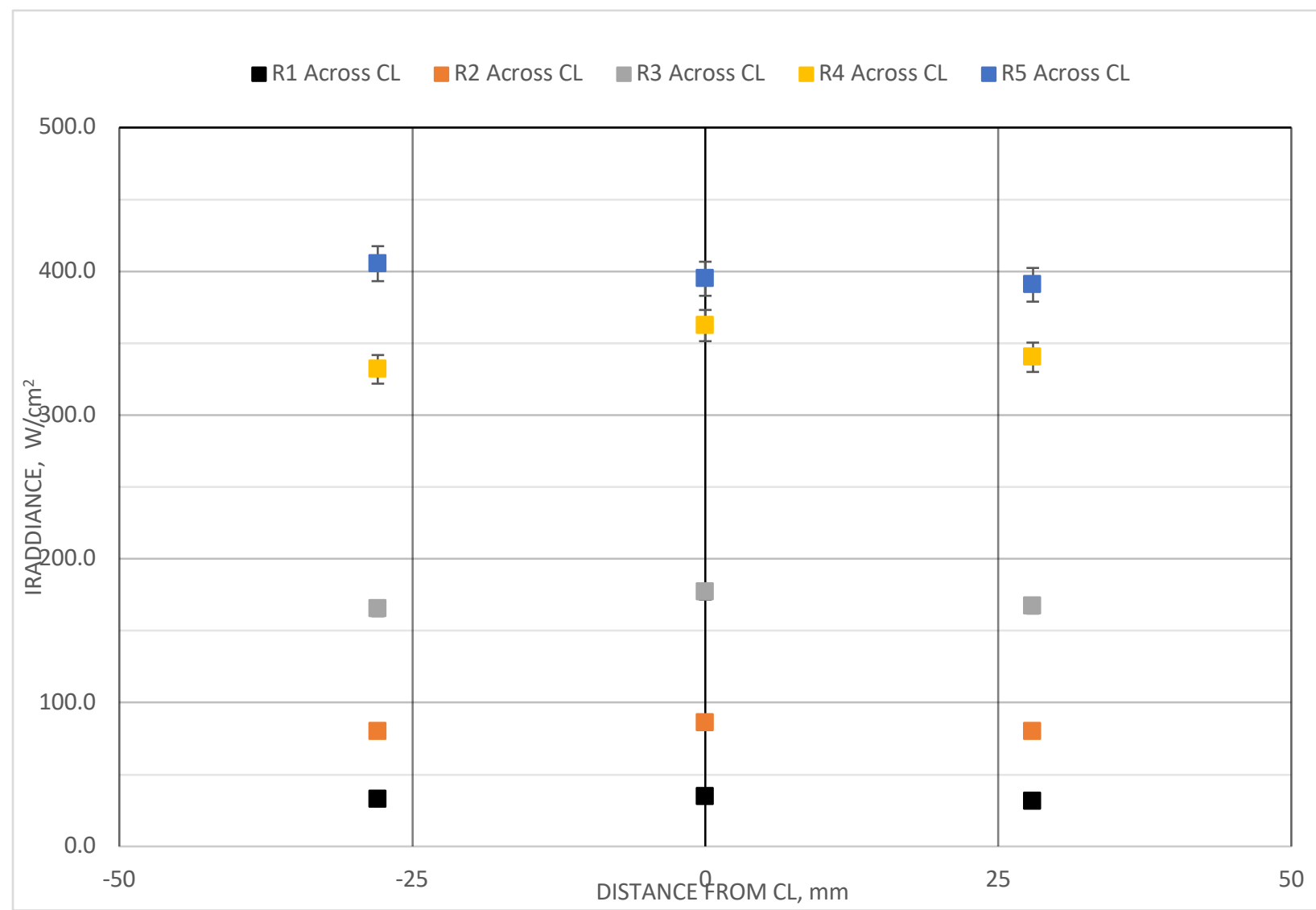

Figure 10. Radiative calibration across centerline. Graphed results from Table 3. Error bars are $\pm 3 \%$.

\section{Convective Calibration Results}

A convective calibration plate was also manufactured and used to evaluate environments from the 9" nozzle. The convective calibration plate contained six Gardon at the same locations as the radiative calibration plate and contained three pressure transducers near the center line. As mentioned before, the convective plate was not coated with black VHT paint, and the convective water-cooled copper plate was assumed to be fully catalytic. The resulting tables and graphs shown below indicate the CWHF for each calorimeter and corresponding surface pressure across the calibration plate. Since multiple runs were achieved for each condition (three runs for condition $\mathrm{C} 1$, two runs for $\mathrm{C} 2$, and five for C3), average heat flux and pressure values for each sensor are shown. Uncertainties for convective runs are estimated to be $\pm 15 \%$, the accepted IHF uncertainty value. 
Table 4. Averaged data from the convective cal plate along centerline. 3 runs were averaged for $\mathrm{C} 1,2$ for $\mathrm{C} 2$, and 5 for $\mathrm{C} 3$.

\begin{tabular}{|c|c|c|c|}
\hline & $\mathrm{C} 1\left(\mathrm{~W} / \mathrm{cm}^{2}\right)$ & $\begin{array}{c}\mathrm{C} 2 \\
\left(\mathrm{~W} / \mathrm{cm}^{2}\right)\end{array}$ & $\begin{array}{c}\mathrm{C} 3 \\
\left(\mathrm{~W} / \mathrm{cm}^{2}\right)\end{array}$ \\
\hline $\mathrm{Cal1}$ & 39 & 106 & 193 \\
\hline $\mathrm{Cal} 2$ & 33 & 88 & 160 \\
\hline $\mathrm{Cal3}$ & 32 & 83 & 143 \\
\hline $\mathrm{Cal} 4$ & 28 & 76 & 144 \\
\hline
\end{tabular}

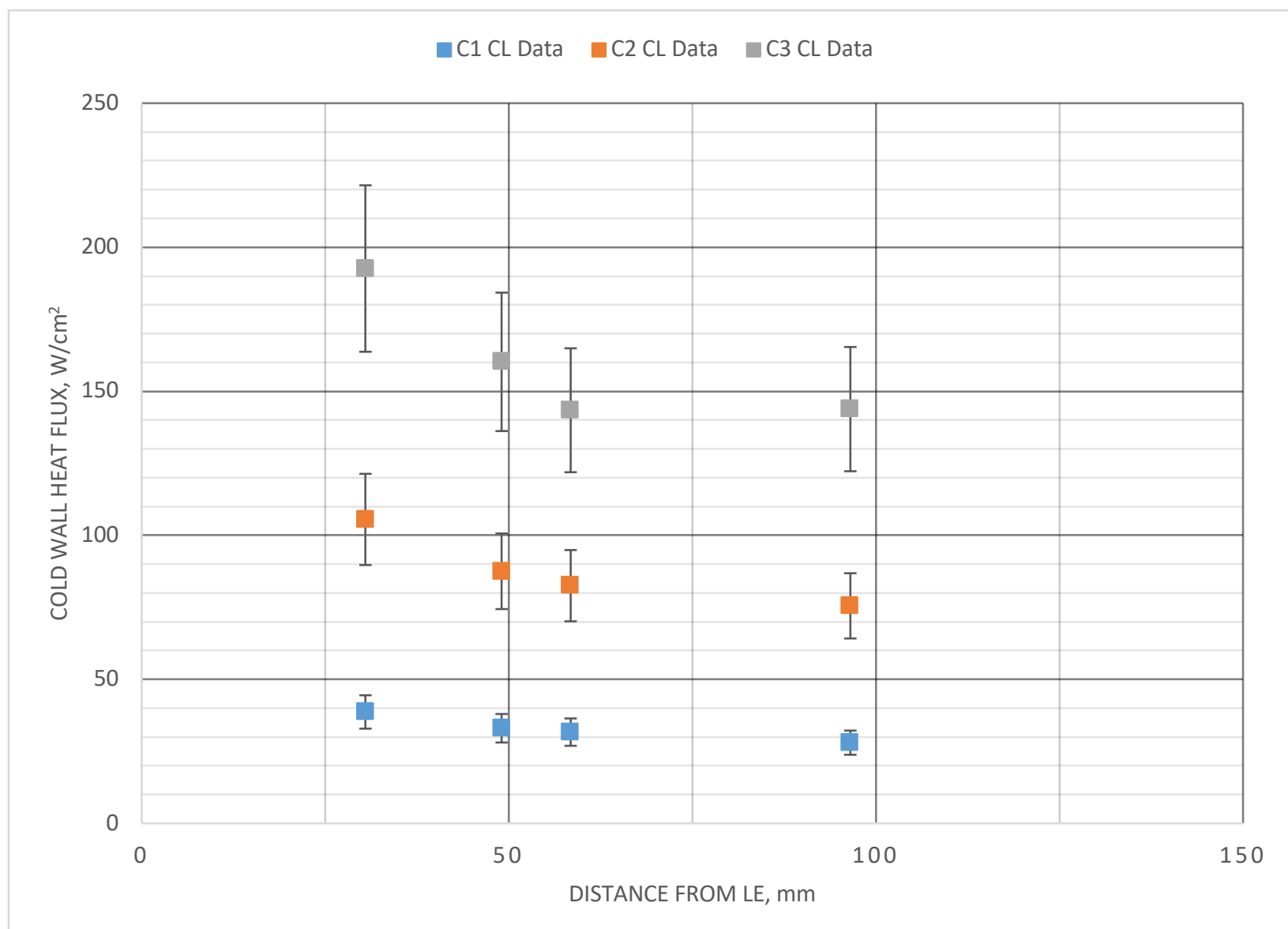

Figure 11. Convective calibration along centerline. Graphed results from Table 4. Error bars are $\pm 15 \%$. 
Table 5. Averaged data from convective cal plate across centerline. 3 runs were averaged for $\mathrm{C} 1,2$ for $\mathrm{C} 2$, and 5 for $\mathrm{C} 3$.

\begin{tabular}{|c|c|c|c|}
\hline & $\mathrm{C} 1\left(\mathrm{~W} / \mathrm{cm}^{2}\right)$ & $\mathrm{C} 2\left(\mathrm{~W} / \mathrm{cm}^{2}\right)$ & $\mathrm{C} 3\left(\mathrm{~W} / \mathrm{cm}^{2}\right)$ \\
\hline Cal 5 & 32 & 79 & 152 \\
\hline Cal 3 & 32 & 83 & 143 \\
\hline Cal 6 & 35 & 81 & 142 \\
\hline
\end{tabular}

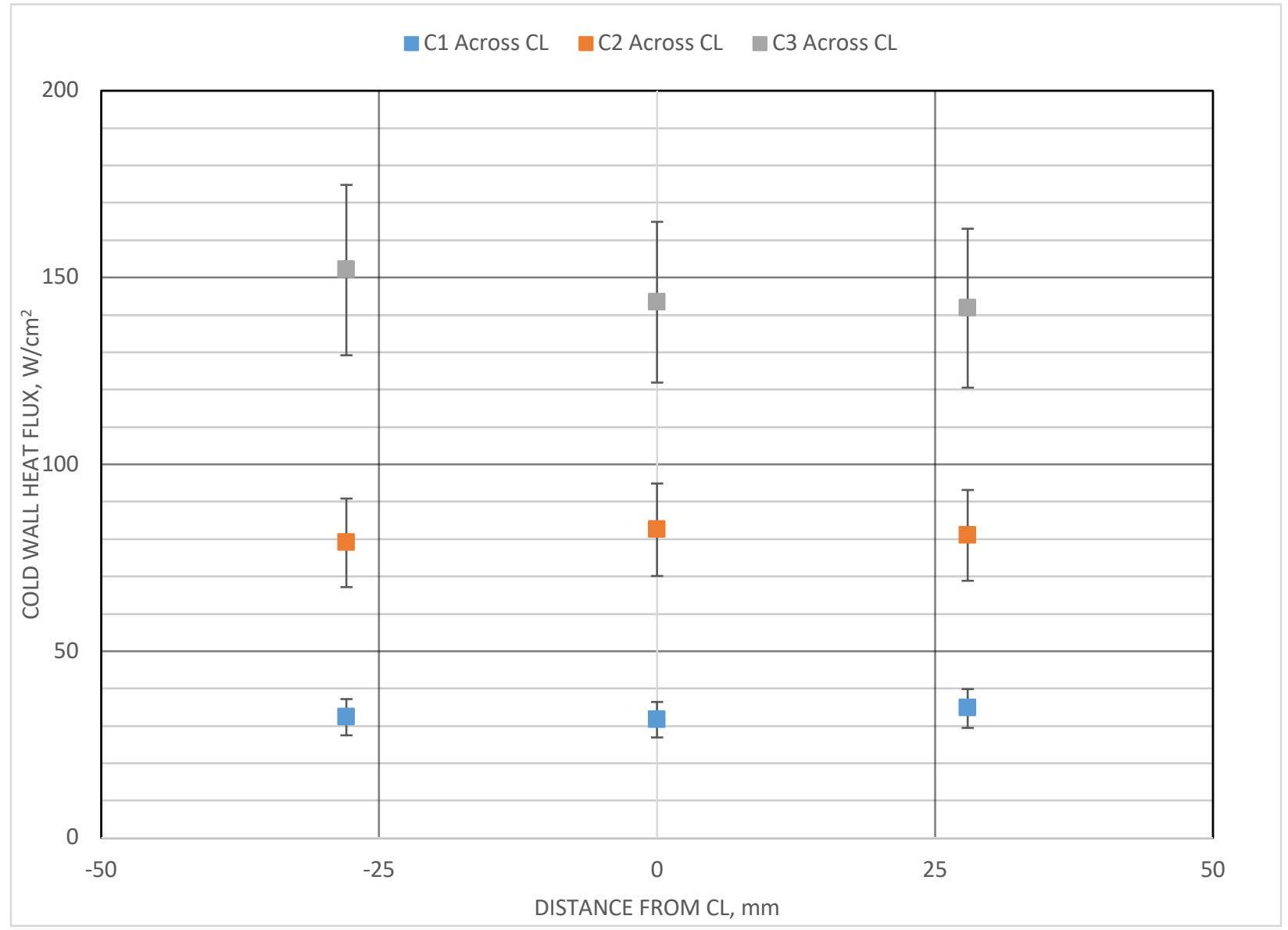

Figure 12. Convective calibration across centerline. Graphed results from Table 5. Error bars are $\pm 15 \%$. 
Table 6. Pressure measurements from convective calibration plate. Data for C1 was averaged over 3 runs, C2 over 2 runs, and C3 over 5 runs.

\begin{tabular}{|c|c|c|c|}
\hline & $\mathrm{C} 1(\mathrm{kPa})$ & $\mathrm{C} 2(\mathrm{kPa})$ & $\mathrm{C} 3(\mathrm{kPa})$ \\
\hline $\mathrm{P} 1$ & 1.7 & 6.7 & 14.4 \\
\hline P2 & 1.5 & 6.1 & 13.2 \\
\hline P3 & 1.1 & 4.9 & 10.9 \\
\hline
\end{tabular}

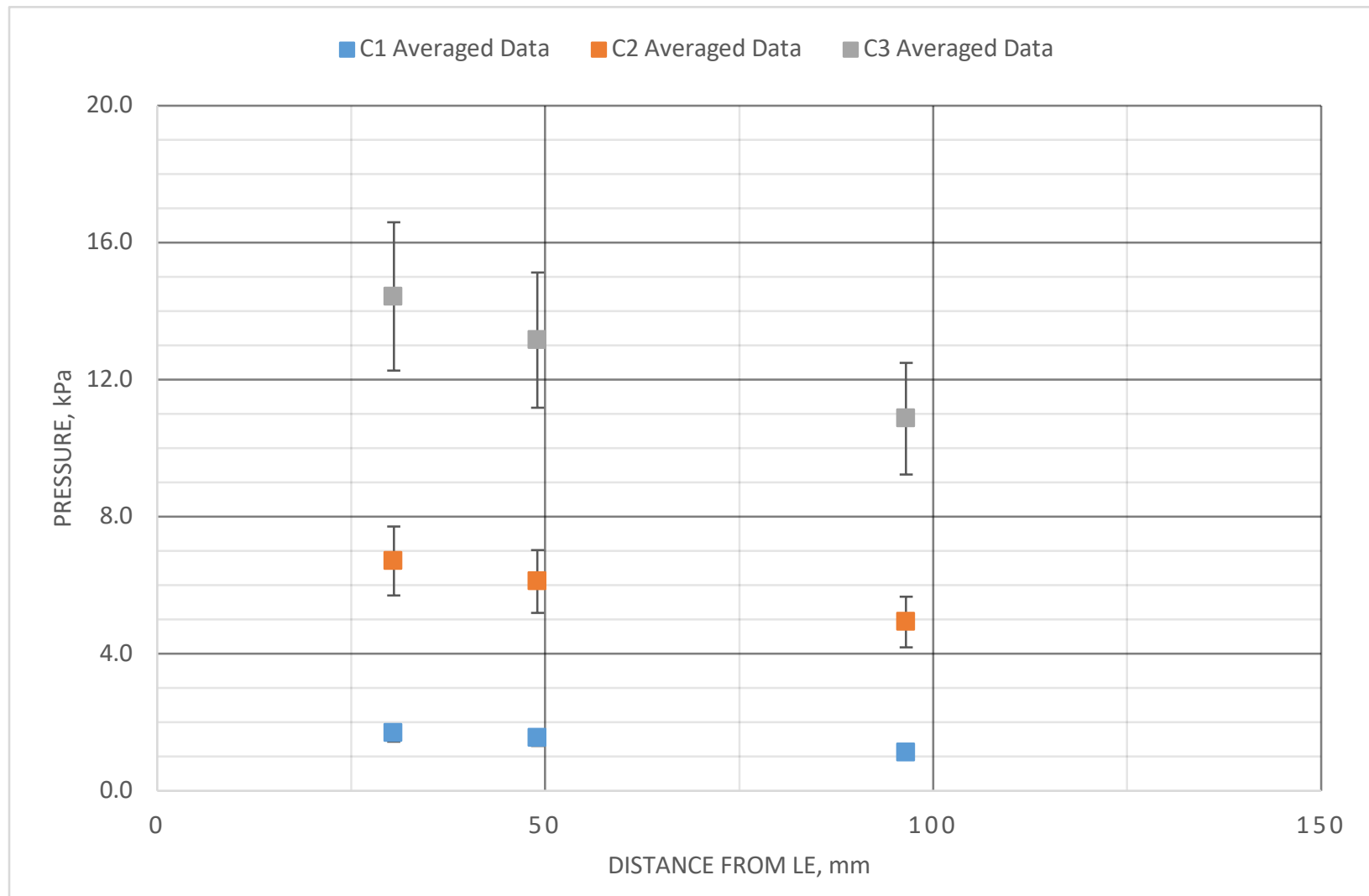

Figure 13. Convective pressure measurements. Graphed results from Table 6. Error bars are shown as $\pm 15 \%$.

As seen in the data, convective heat flux and pressure significantly decrease in the direction of the flow due to the flow expansion from the nozzle exit. Similar to radiative runs, run-to-run repeatability across all convective conditions was fairly good, within $10 \%$.

\section{B. RCG-Tile Calibration Plate}

The water-cooled calibration plates helped to quantify surface environments near the middle of the $152-\mathrm{mm} \times 152-$ mm test plate; however, they did not fully cover the test plate area. Therefore, an RCG-coated, L1-2200 plate was fabricated with 17 type - R, near-surface thermocouples throughout the test plate area (Figure 14) to capture a more complete understanding of the heating distribution on the test plate surface. Due to heating limitations of RCG coated L1-2200, the test plate was only evaluated at low radiative and convective conditions R1 and C1. 


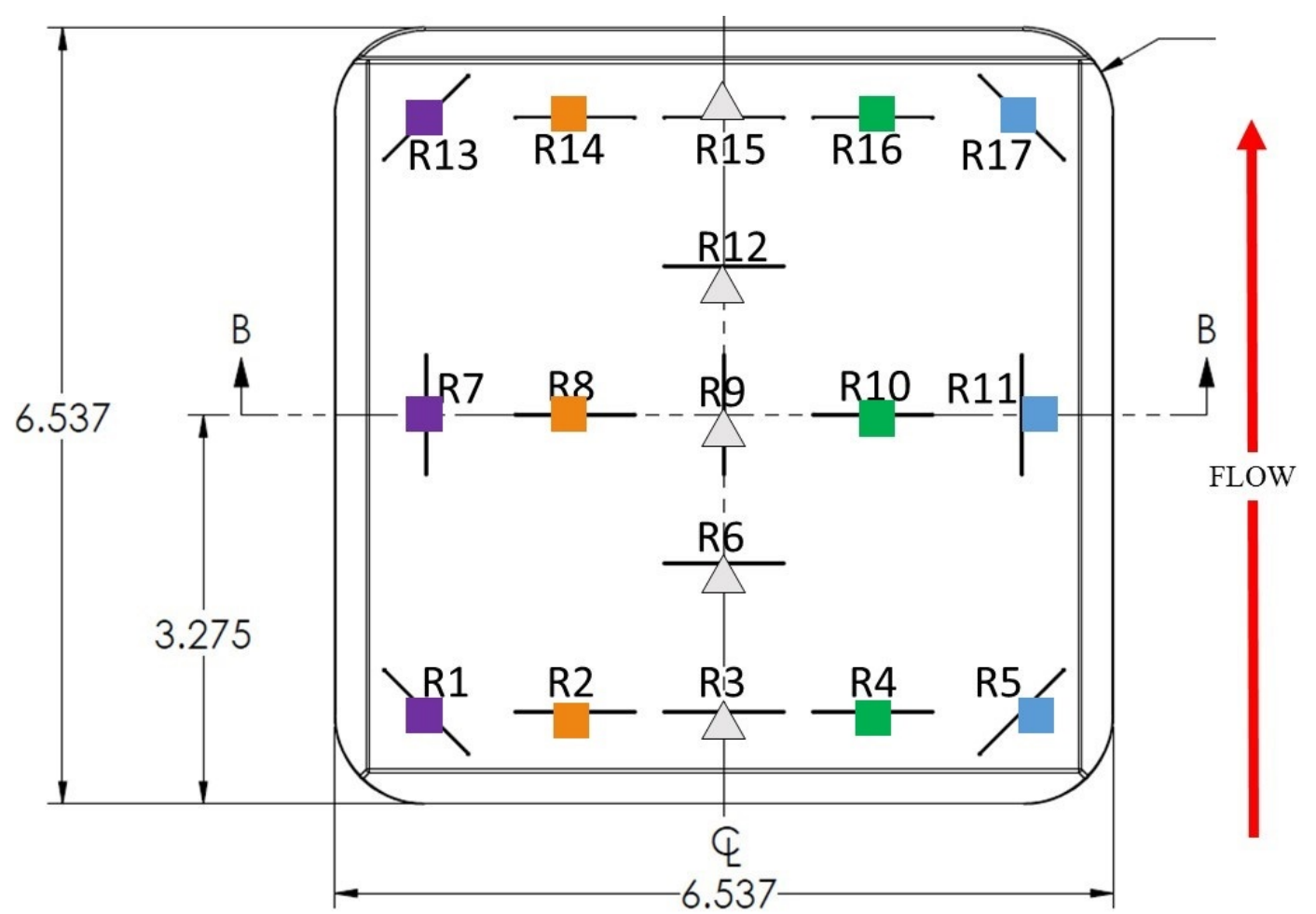

Figure 14. RCG L1-2200 coated plate with 17 near-surface TCs. Markers on Figures 15 and 16 match locations shown here.

\section{Radiative RCG Results}

This RCG coated tile was exposed to relatively low levels of radiant heat to reduce the risk of damaging the tile. The tile was exposed to the R1 Set Point for 100 seconds for only 1 run. Temperature results are shown in Figure 15. 


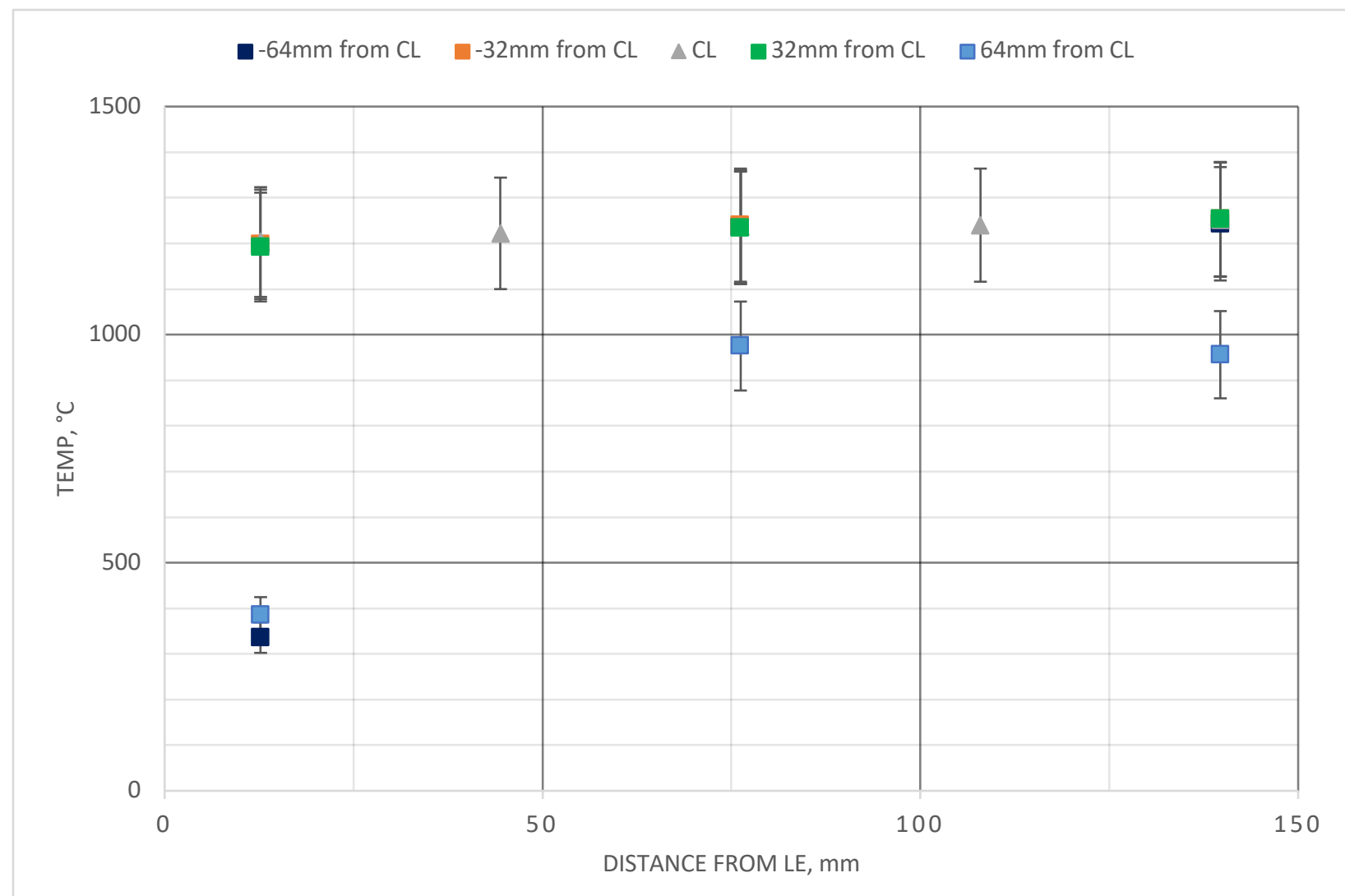

Figure 15. Radiative RCG tile results. See figure 14 for positioning. Error bars are shown with $\pm 10 \%$.

As seen in the figure, the temperatures are similar except for certain thermocouples located on the very edge of the beam. This is a result of having the square slightly misaligned to the block, which was confirmed by IR video. Along the centerline, temperatures average to $1230 \pm 19^{\circ} \mathrm{C}$. It is expected that all temperatures would come close to this after alignment. This situation demonstrates that laser misalignment, even by a few centimeters, can lead to suboptimal data. The cause of this particular misalignment was that the target plate, located on a different swing arm, was nearly half an inch off from the RCG tile's final position. After this run, alignment procedures were changed to align directly to the model when possible. There were no misaligned shots for the remainder of the IST. It is also worth noting that the incident laser beam always maintained alignment during exposures.

\section{Convective RCG Results}

Two RCG tile data runs were collected for convective only heating and averaged in Figure 16. Like the calibration plate data, the RCG tile data shows a decreasing temperature along the stream similar to the behavior of the heat flux and pressure measurements as the flow expands from the nozzle exit. 


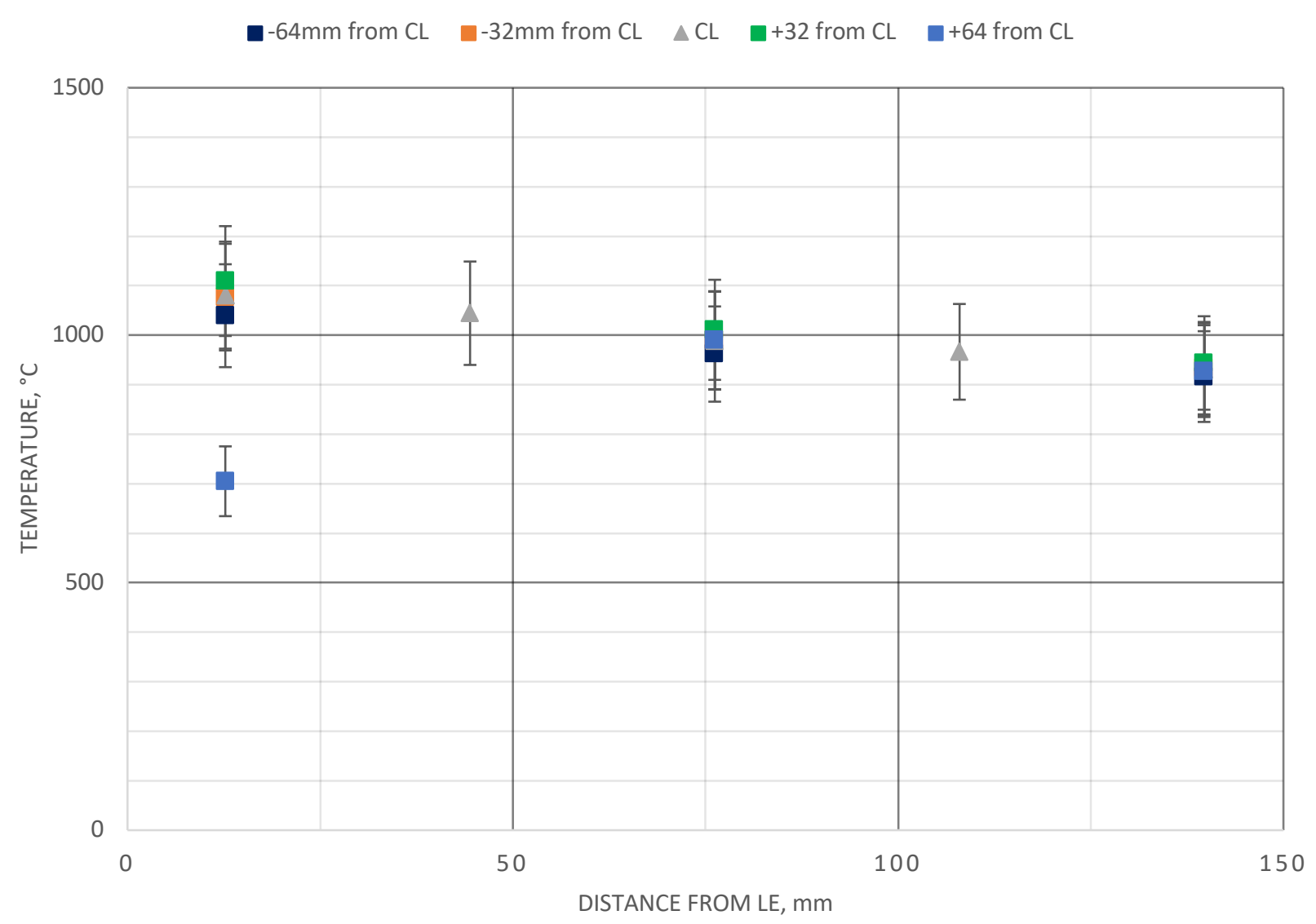

Figure 16. Convective RCG tile results along stream. Convective RCG data averaged over 2 runs. Error bars are shown with $\pm 10 \%$.

Centerline temperatures from the convective runs and the radiative run are listed in Table 7 and illustrated in Figure 17. The comparison indicates that, at comparable heat flux, near-surface temperatures are $10-25 \%$ higher in radiative heating than in convective heating.

Table 7. Near-surface temperatures and heat flux along CL of the RCG-coated tile plate as measured during conditions $\mathrm{R} 1$ and $\mathrm{C} 1$.

\begin{tabular}{|c|c|c|c|c|c|c|}
\hline & TC_R3 & TC_R6 & TC_R9 & TC_R12 & TC_R15 & $\begin{array}{c}\text { CWHF } \\
\left(\mathrm{W} / \mathrm{cm}^{2}\right)\end{array}$ \\
\hline Radiative & 1203 & 1222 & 1237 & 1240 & 1252 & 32 \\
\hline Convective & 1081 & 1044.5 & 989 & 966.5 & 931 & $39-28$ \\
\hline
\end{tabular}




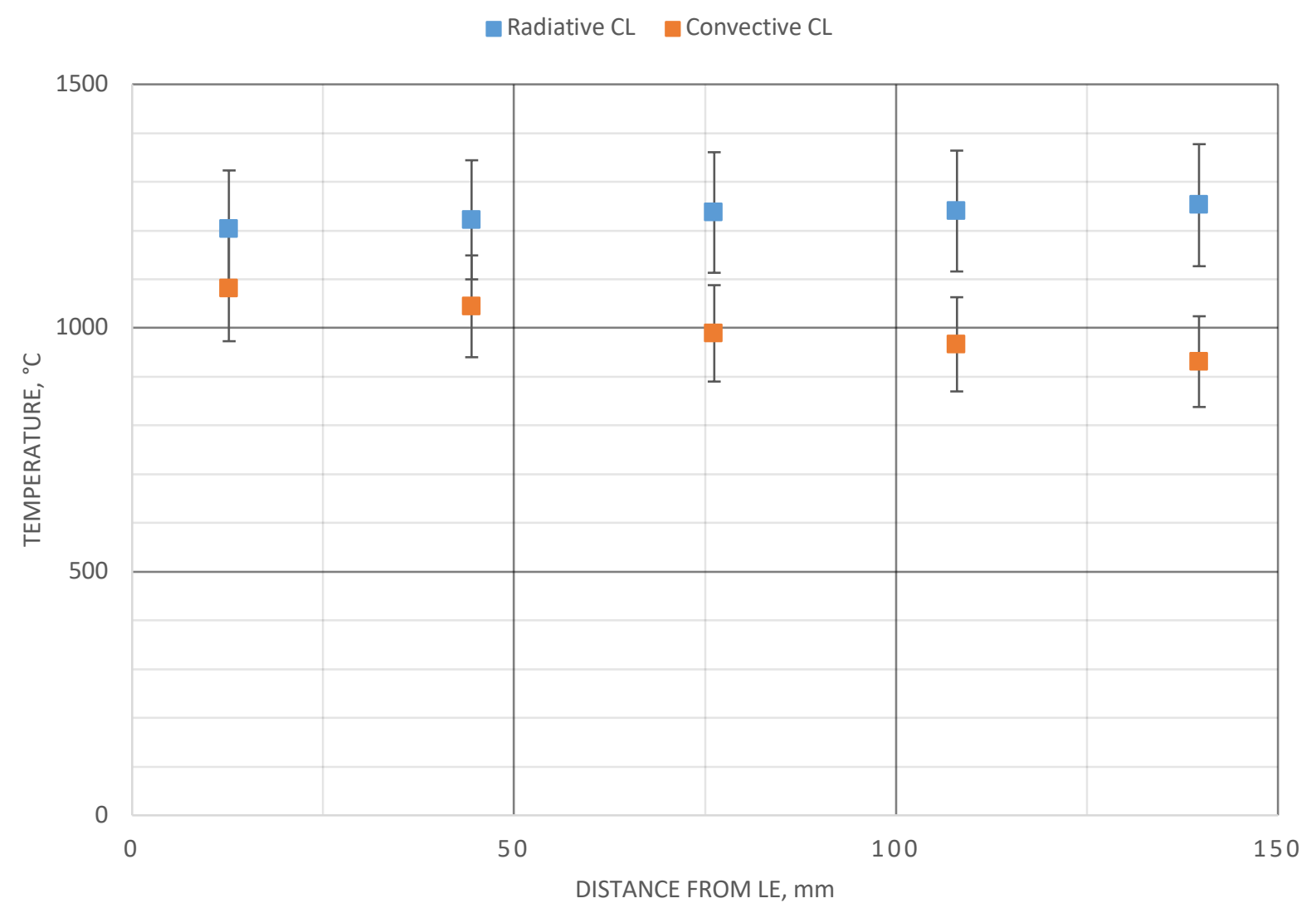

Figure 17. Comparing RCG temperature along center line. Surface temperatures along CL of the RCGcoated tile plate as measured during conditions $\mathrm{R} 1$ and $\mathrm{C} 1$.

\section{Avcoat Results}

The primary purpose of testing Avcoat articles in the LEAF-Lite IST was to demonstrate the feasibility of testing Orion's ablative heatshield material at both independent and combined heating environments prior to proceeding with future test campaigns dedicated to characterizing the thermal and ablative performance of Orion TPS. Material response data were gathered from each test article, however, an in-depth discussion of the results is beyond the scope of this paper.

The IST included five 152-mm x 152-mm Avcoat test plates, listed in Table 8: one exposed to radiative heating, one exposed to convective heating, and three exposed to varying combinations of radiative and convective heating. No anomalies were observed during Avcoat tests, an example of which is illustrated in Figure 18. Images of post-test samples, shown in Figure 19, demonstrate acceptable performance across the range of conditions that were tested.

Table 8. Summary of radiative and convective heat flux (measured at Cal2 location) for Avcoat.

\begin{tabular}{|c|c|c|c|}
\hline $\begin{array}{c}\text { Avcoat } \\
\text { Sample }\end{array}$ & $\begin{array}{c}\text { Radiative Heat Flux } \\
\left(\mathrm{W} / \mathrm{cm}^{2}\right)\end{array}$ & $\begin{array}{c}\text { Convective Heat Flux } \\
\left(\mathrm{W} / \mathrm{cm}^{2}\right)\end{array}$ & $\begin{array}{c}\text { Total Heat Flux } \\
\left(\mathrm{W} / \mathrm{cm}^{2}\right)\end{array}$ \\
\hline 1 & 168 & 0 & 168 \\
\hline 2 & 0 & 160 & 160 \\
\hline 3 & 83 & 88 & 171 \\
\hline 4 & 168 & 160 & 328 \\
\hline 5 & 340 & 160 & 500 \\
\hline
\end{tabular}




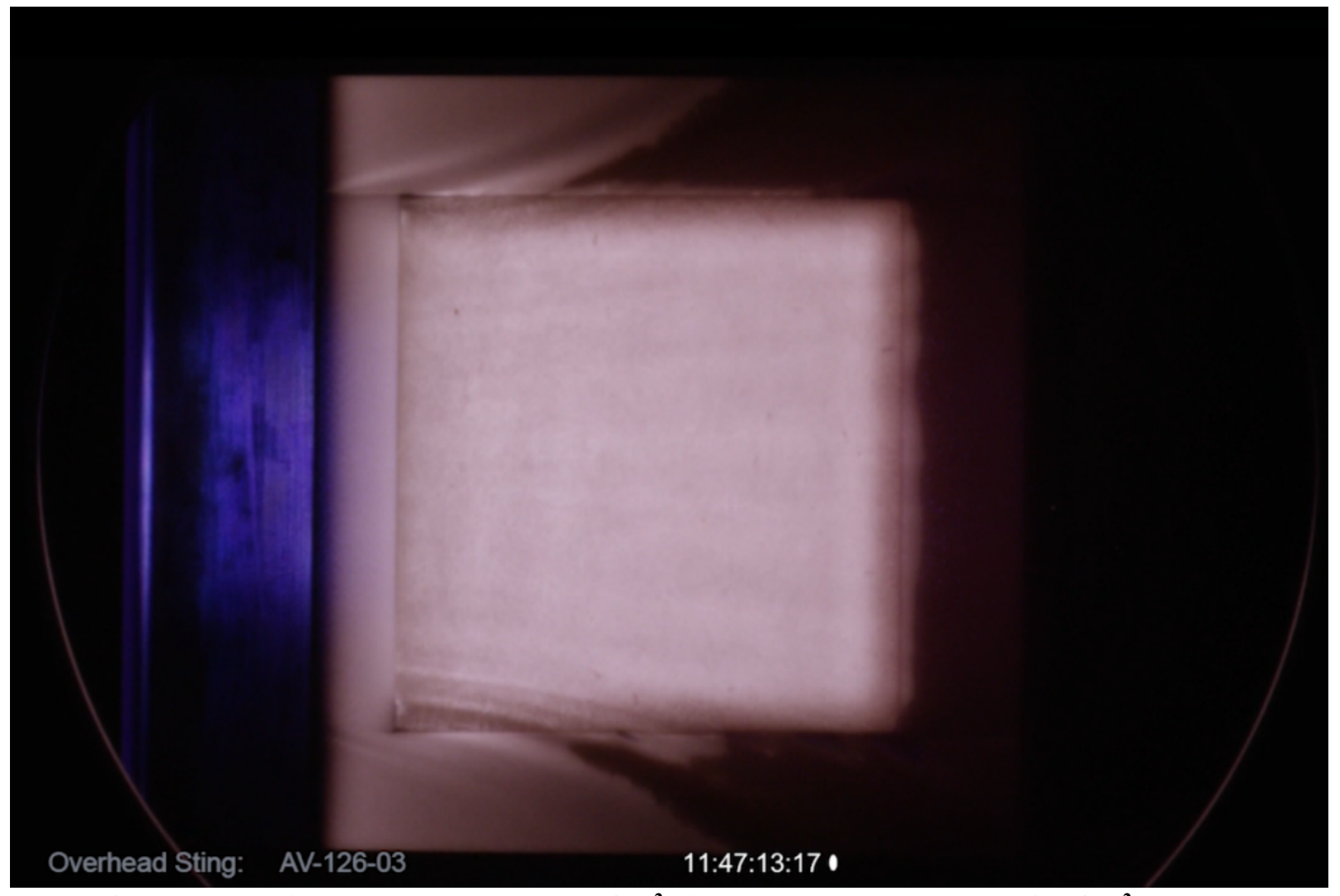

Figure 18. Video still of Avcoat exposed to $160 \mathrm{~W} / \mathrm{cm}^{2}$ of convective (arc-jet) and $168 \mathrm{~W} / \mathrm{cm}^{2}$ radiative (laser) heat. Convective flow from left to right. 
Sample $1.168 \mathrm{~W} / \mathrm{cm}^{2}$ radiative at $120-\mathrm{s}$ exposure
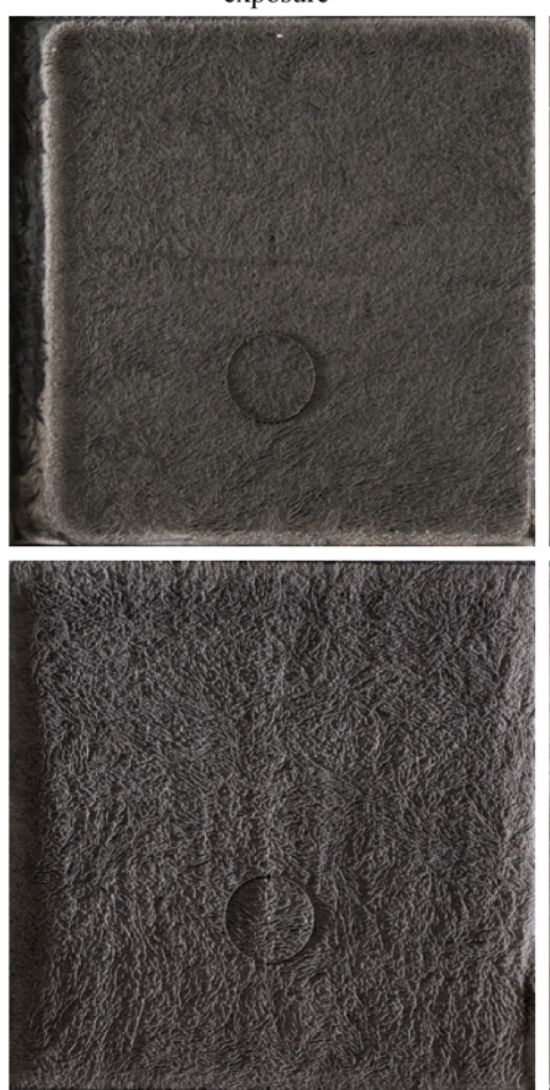

Sample 4. $168 \mathrm{~W} / \mathrm{cm}^{2}$ radiative +160 $\mathrm{W} / \mathrm{cm}^{2}$ convective at 60 -s exposure
Sample 2. $160 \mathrm{~W} / \mathrm{cm}^{2}$ convective at 120 -s exposure
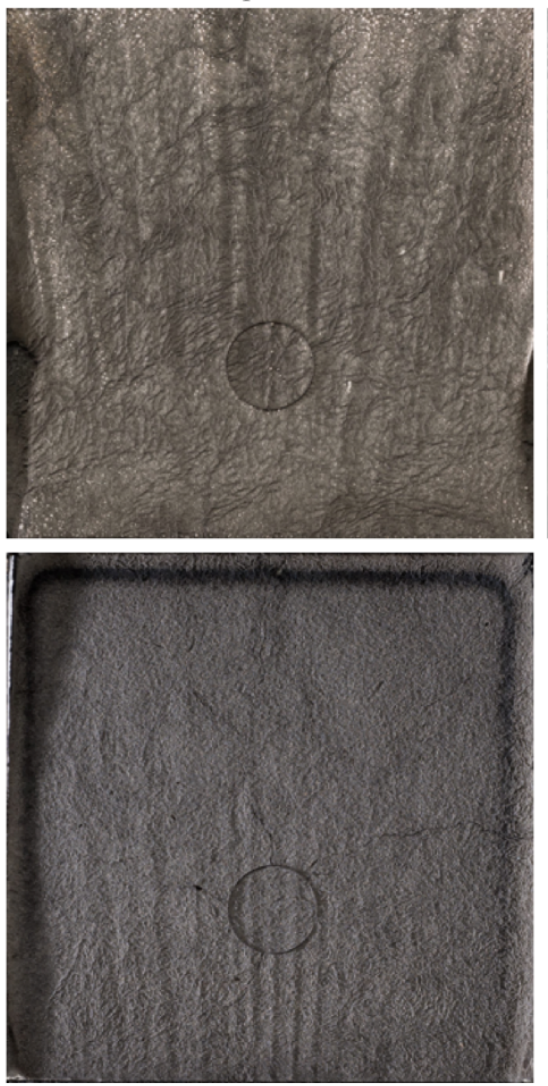

Sample 5. $340 \mathrm{~W} / \mathrm{cm}^{2}$ radiative +160

$\mathrm{W} / \mathrm{cm}^{2}$ convective at 30 -s exposure
Sample $3.83 \mathrm{~W} / \mathrm{cm}^{2}$ radiative +88 $\mathrm{W} / \mathrm{cm}^{2}$ convective at 1200 -s exposure

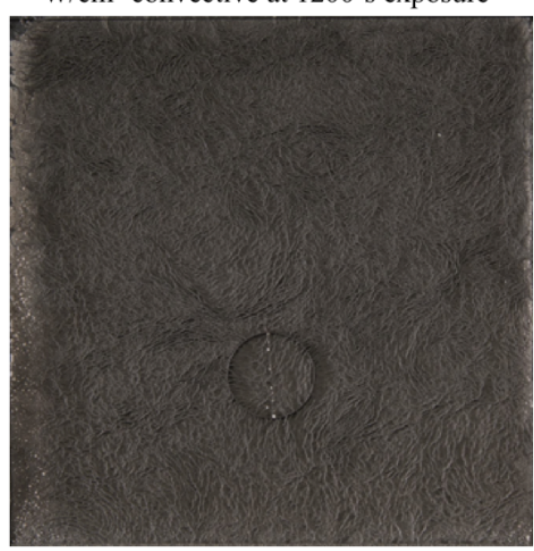

Figure 19. Post-test photographs of Avcoat samples tested in LEAF-Lite.

The most discernable visual observations can be made from Avcoat Samples 1, 2 and 3, which were exposed to different modes of heating but were tested at the same durations at nominally similar heat fluxes measured at the Cal 2 location of the calorimeter plates. The charred surfaces of Sample 1, which was radiatively heated, and Sample 3, which was exposed to a 1:1 ratio of radiative and convective heating, are uniformly flat, very dark, and display only small amounts of glass at the periphery, suggesting that the surfaces were hot enough for glass vaporization. Meanwhile, the surface of Sample 2 was affected by Goertler vortices, artifacts of convective heating. Sample 2 was also covered entirely in glass melt, making the surface visibly lighter and indicating that the surface was only hot enough to melt but not vaporize glass.

\section{Concluding remarks and Future Improvements}

The LEAF-Lite system is a one-of-a-kind test facility. Relevant testing has been demonstrated and provides a more flight-like environment with combined convective and radiative heating. The requirements for the maximum laser power and the size of the illuminated area of the test article sizes were derived primarily from the Orion EM-1 TPS flight qualification program and we have demonstrated the current capability to achieve these requirements. This new addition to the Interaction Heating Facility at NASA Ames allows TPS samples to be simultaneously exposed to radiative and convective heating conditions. Currently, two 50-kW CW lasers are capable of projecting a uniform square, 152-mm x 152-mm, beam onto a wedge test article inside the facility's vacuum test chamber. Later in 2018 , the LEAF-Lite system will expand and add two additional 50-kW CW lasers and provide $100 \mathrm{~W} / \mathrm{cm}^{2}$ of radiant heat on a 432-mm x 432-mm wedge model while a truncated semi-elliptic nozzle attached to the IHF will provide convective heat.

In the future, further upgrades and improvements to the laser system are likely as we learn more from the Orion flight test qualification program. Comparing our ground data with flight data will also lead to further 
modifications and improvements. It is also possible to change the size and shape of the beam to a rectangle or another shape by changing the integrators and other optics in the beam paths if future customers require such changes. It may even be possible to project a non-uniform Gaussian beam into the test chamber for even higher irradiances. Although the beam profile would not be uniform, the irradiance would increase to $\mathrm{kW} / \mathrm{cm}^{2}$ intensities. These smaller but more powerful spot sizes are useful for testing planetary robotic entry missions to Venus, gas and ice-giants where there is a much higher shock layer radiation compared to Orion EM-1. We are also currently evaluating if it is feasible and safe to direct all four $50-\mathrm{kW}$ lasers on to a $152-\mathrm{mm} \times 152-\mathrm{mm}$ square instead of the $432-\mathrm{mm} \times 432-\mathrm{mm}$ square under vacuum conditions. This system is very early on in its life and possible configurations are still being imagined.

Preliminary testing of Avcoat samples was successful and further testing of the Orion EM-1 heat shield occurs later this year. This unique facility enables better understanding, testing, and validating for future TPS materials due to simultaneous radiative and convective heating, a feat that was previously not possible before this system.

\section{Acknowledgments}

The authors would like to thank all of those involved who help build, design, and construct LEAF-Lite along with the numerous people who helped operate the laser and IHF during IST. We would also like to thank the NASA Orion TPS Insight/Oversight Project and Code T management, who have supported LEAF-Lite from its beginning.

\section{References}

\footnotetext{
[1] Timothy Cichan, Scott D. Norris, and Paul Marshall. "Orion: EFT-1 Flight Test Results and EM-1/2 Status", AIAA SPACE 2015 Conference and Exposition, AIAA SPACE Forum, (AIAA 2015-4414)
}

${ }^{[2]}$ J. LUNDELL, R. DICKEY, and L. OTTEN. "The CO2 gasdynamic laser as a high-intensity radiation facility", 13th Aerospace Sciences Meeting, Aerospace Sciences Meetings, (AIAA 75-177)

[3] ASTM E511-07(2015), Standard Test Method for Measuring Heat Flux Using a Copper-Constantan Circular Foil, Heat-Flux Transducer, ASTM International, West Conshohocken, PA, 2015, www.astm.org 